\title{
Epithelial-Cadherin Expression Is Associated With Better Recurrence-Free and Overall Survival in Invasive Lobular Breast Cancer in Mexican Women
}

\author{
Ricardo Fernandez-Ferreira, ${ }^{\mathrm{a}, \mathrm{c}}$, Rita Dorantes-Heredia ${ }^{\mathrm{b}}$, Daniel Motola-Kuba ${ }^{\mathrm{a}}$, \\ Jose-Manuel Ruiz-Morales ${ }^{\text {a }}$, Gabriela Alvarado-Luna ${ }^{a}$, Ileana Mac Kinney-Noveloa, \\ Wendy-Rossemary Munoz-Montano ${ }^{a}$, Kevin-Joseph Fuentes-Calvo ${ }^{\mathrm{a}}$
}

\begin{abstract}
Background: There are different clinicopathological characteristics that are associated with the prognosis in patients with breast cancer. To date, the prognostic valor of for epithelial cadherin (E cadherin) expression in invasive lobular breast cancer remains unknown.
\end{abstract}

Methods: A retrospective single-center study that included 207 patients with primary invasive lobular breast cancer was conducted. The primary outcome was to report the correlation of the different clinical pathological characteristics including the expression of epithelialcadherin (E-cadherin) in invasive lobular breast cancer in Mexican women with recurrence-free survival (RFS) and overall survival (OS).

Results: After 11 years of follow-up of patients with invasive lobular breast cancer, RFS was $89.4 \%$ and OS of $96.1 \%$. The best prognosis in RFS was in patients with negative nodes $95.2 \%(\mathrm{P}=0.0001)$ and OS was $98.6-100 \%(\mathrm{P}=0.0001)$. Regarding tumor size, an RFS of $98.3 \%$ was observed in those measuring $\leq 2 \mathrm{~cm}(\mathrm{P}=0.0001)$ and OS of $99.2 \%(\mathrm{P}=0.0001)$. Negative Her2 was related to an RFS of $92.1 \%(\mathrm{P}=0.0001)$, and had better OS of $98.3 \%(\mathrm{P}=0.0001) . \mathrm{Ki67}$ proliferation index $\leq 14 \%$ was associated with an RFS of $93.2 \%$ (P $=0.005)$. Negative lymph vascular invasion (LVI) increases the RFS of $91.8 \%(\mathrm{P}=0.032)$. The rate of positive expression of E-cadherin was associated with an increase in the RFS of $97.4 \%$, with a mean of $128.6 \pm 2.4$ months $(95 \%$ confidence interval $(\mathrm{CI}): 123.75-133.45$ months) compared to the absence of expression E-cadherin: signal

Manuscript submitted October 7, 2021, accepted November 27, 2021

Published online December 28, 2021

ancology Medicine Department, Comprehensive Oncology Center "Diana Laura Riojas de Colosio", Medica Sur Clinic \& Foundation, Mexico City, Mexico

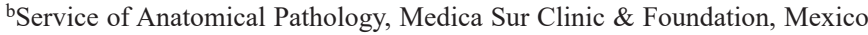
City, Mexico

${ }^{\mathrm{c} C o r r e s p o n d i n g ~ A u t h o r: ~ R i c a r d o ~ F e r n a n d e z-F e r r e i r a, ~ D e p a r t m e n t ~ o f ~ O n c o l-~}$ ogy Medicine, Comprehensive Oncology Center "Diana Laura Riojas de Colosio", Medica Sur Clinic \& Foundation, Puente de Piedra \#150, Colonia Toriello Guerra, Delegacion Tlalpan, Mexico City, Mexico.

Email: ricardo.fdez.ferreira@comunidad.unam.mx

doi: https://doi.org/10.14740/wjon1426 $\log$ ratio (SLR) $68.9 \%$, a mean of $95 \pm 6$ months (95\% CI: 83.28 106.88 months), $\mathrm{P}<0.001$. When the OS was analyzed, the presence of E-cadherin expression increased the OS of $100 \%$ vs. $86.9 \%$ with the absence, $\mathrm{P}=0.015$.

Conclusions: The prognostic impact of the different clinicopathological characteristics known worldwide was confirmed. Results of the analysis in the presented study indicate that positive expression of Ecadherin correlates with an improvement in OS and RFS in invasive lobular breast cancer in Mexican women.

Keywords: Clinical; Pathological; Invasive lobular breast cancer; Ecadherin; Overall survival; Recurrence; Prognostic

\section{Introduction}

Breast cancer is a public health problem in the world. It is the first most commonly diagnosed cancer worldwide, including low- and middle-income countries with an incidence of $11.7 \%$, and is the fourth cause of dead (6.9\%) in the world. The incidence rates are highest in North America, Australia/New Zealand, and in western and northern Europe and lowest in Asia and Sub-Saharan Africa. The incidence in Mexico is 15.3\% (the first most common) and the first cause of mortality (8.8\%) in 2020 [1-4].

Infiltrating lobular carcinomas are the second most common type of invasive breast cancer, accounting for about 5-10\% of invasive lesions. Some pathologists have used lack of immunohistochemical staining for epithelial-cadherin (E-cadherin) to distinguish invasive lobular carcinoma from invasive duct carcinoma, and these tumors are characterized microscopically by small cells that insidiously infiltrate the mammary stroma and adipose tissue individually and in a single file pattern, often growing in a target-like configuration around normal breast ducts, frequently inducing only minimal fibrous reaction [5].

E-cadherin is an adhesive protein (maintain tissue continuity) that play a crucial role in the process of regional invasion, in migration of cancerous cells, and additionally in later maintenance in the remote organs. The loss of E-cadherin expression is observed among patients suffering from: breast, 
prostate, bladder, lung and stomach cancer, and this correlates with detrimental prognostic factor, higher level of malignancy, presence of metastasis in axillary lymph nodes, lack of estrogen and progestin receptors, and presence of recurrence, while the increase of E-cadherin expression has been associated with a better prognosis [6-9].

There are different clinicopathological characteristics (tumor size, lymphovascular invasion, perineural invasion, histological grade, Ki67 proliferation index, etc.) that are associated with the prognosis in patients with breast cancer, especially in progression-free survival, local and metastatic recurrences, as well as in overall survival (OS). Despite that the value of Ecadherin in patients with breast cancer remains contradictory, it is probably a very important prognostic factor [5-13].

The objective of this study is to report the correlation of different clinicopathological characteristics in invasive lobular breast cancer in Mexican women treated in a private tertiary care hospital, with recurrence-free survival (RFS) and OS.

\section{Materials and Methods}

\section{Patients}

An exhaustive review of 207 clinical records of patients with primary invasive lobular breast cancer who were treated at Medical Sur Hospital between January 2010 and December 2018 was performed. Of the 207 patients with invasive lobular breast cancer, 100 records were selected in which the analysis of the expression of E-cadherin was reported. Case inclusion criteria were as follows: diagnosis according to breast pathology; no history of radiotherapy, chemotherapy or endocrine therapy prior to admission; Karnofsky performance status score of $\geq 80$ points and surgery performed with all samples identified by three pathology experts for histopathological identification of breast invasive lobular carcinoma; no other malignancy history; preoperative consent specimens collected and informed consent obtained; and approval was provided by the Medical Sur Hospital Ethics Committee. Case exclusion criteria were as follows: incomplete clinical records; breast invasive ductal carcinoma and carcinoma in situ; and preoperative chemotherapy, radiotherapy or endocrine therapy. In addition, other exclusions were other specific types of breast tumors (sarcoma, micropapillary carcinoma, lymphoma, inflammatory breast cancer, male breast carcinoma and gestational breast cancer). The study was conducted in compliance with the ethical standards of the responsible institution on human subjects as well as with the Helsinki Declaration.

\section{Methods}

A retrospective, non-randomized, observational, descriptive, single-center study was conducted. Follow-up phone calls were made to identify associated information; and the information recorded in the case was approved by the patient. The patients' medical records were used to record identity, phone numbers, addresses, and other personal information, including zip code, gender, and breast cancer history. For patients who could not be contacted, their last assessment for outpatient consultation, hospitalization or discharge was used.

\section{Statistical analysis}

All data were shown as the mean \pm standard deviation and analyzed using a univariate analysis, $\chi^{2}$ test or exact probability method. A survival analysis was performed using the KaplanMeier method, with the log-rank test. The 11-year RFS was evaluated (from the time of the operation to the appearance of failure), as well as the 11-year OS time (from time of the operation to time of death). The Wilcoxon test with Gehan's modification was used in testing the differences between the periods of survival among the examined patients. The SPSS 18.0 statistical software (SPSS, Inc., Chicago, IL, USA) was used. $\mathrm{P}<0.05$ indicated that the difference was statistically significant.

\section{Results}

\section{General characteristics}

From 2010 to 2018, 207 records of patients with invasive lobular cancer were analyzed; from which $52.2 \%$ were $>60$ years, $72.9 \%$ already had menopause at diagnosis, $72.9 \%$ had no history of smoking.

The most frequent molecular subtype was luminal in $94.7 \%$ and histological grade was Scarff-Bloom-Richardson $2(63.8 \%)$. Lymphovascular invasion was reported positive in $23.7 \%$ of cases, positive margin in $15 \%$, and perineural invasion in $15.9 \%$. The expression of E-cadherin was analyzed in $48.3 \%$ (100/207 patients), positive expression was reported in 39 patients $(39 \%)$ and lack expression in $61 \%$ of the patients analyzed (Table 1).

In relation to the clinical stage (CS), localized disease (CS I-IIB: T2N1) was in $178(86 \%)$ of the patients, with CS IB being the most frequent in $92(44.5 \%)$, followed by clinical stage IIA $(24.2 \%)$, locally advanced CS IIB (T3N0) and IIIA-IIIC disease occurred in 25 (12\%) of patients, and metastatic CS IV disease was reported in four patients $(2 \%)$.

Ninety-eight $(47.3 \%)$ of the patients underwent modified radical mastectomy and $106(51.2 \%)$ breast-conserving surgery; all patients received adjuvant treatment according to clinical stage and molecular subtype; follow-up was performed in consultation of medical oncology, reporting eight (3.9\%) deaths until 2021.

\section{Recurrences}

Of the 207 patients analyzed, $22(10.6 \%)$ had recurrences, five $(2.4 \%)$ were local recurrences, of which two (1\%) had contralateral recurrence, seven $(3.4 \%)$ had systemic recurrence and $10(4.8 \%)$ had recurrence local and systemic. Of these recurrences, three (1.4\%) had visceral recurrence (liver, lung), $10(4.8 \%)$ had non-visceral recurrence (lymph node and bone), 
Table 1. General Characteristics

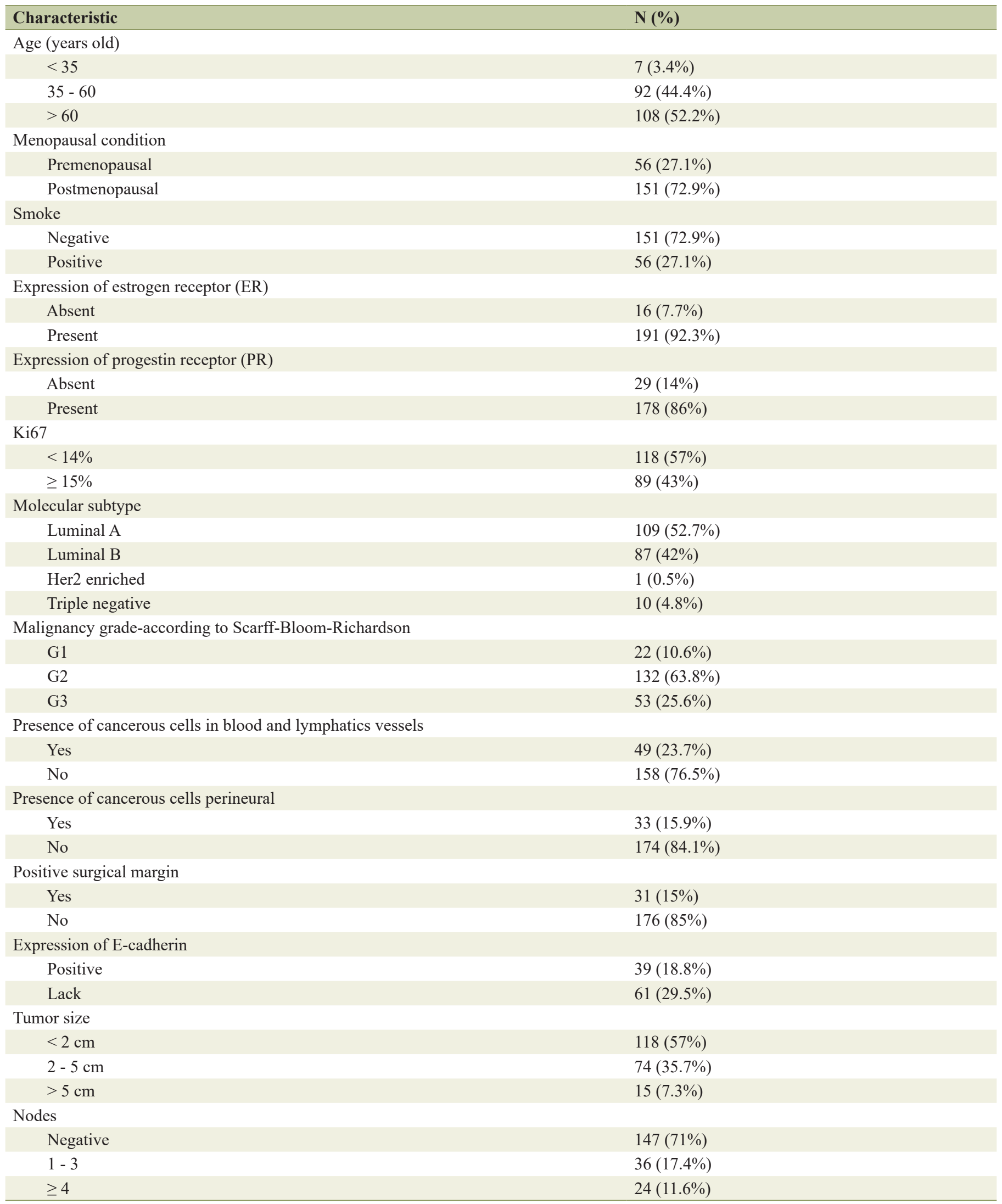




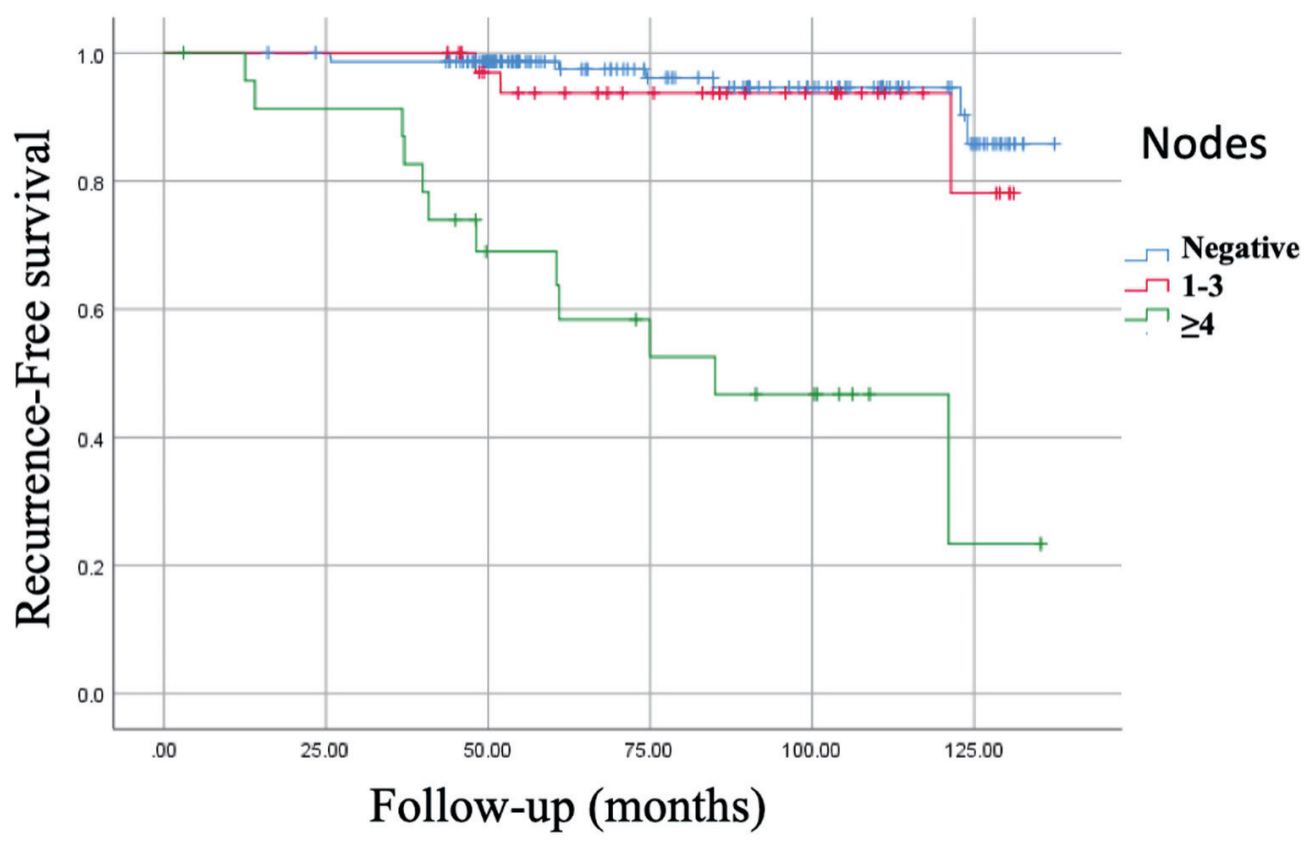

Figure 1. Kaplan-Meier curve of recurrence-free survival (RFS) of nodes. RFS of negative nodes: $95.2 \%, 132.06 \pm 1.93$ months (95\% Cl: 128.27 - 135.86 months). RFS of 1 - 3 positive nodes: $91.7 \%, 124.52 \pm 3.67$ months (95\% Cl: $117.31-131.73$ months). RFS of $\geq 4$ positive nodes: $50 \%, 85.89 \pm 9.59$ months (95\% Cl: $67.08-104.69$ months), $\mathrm{P}=0.0001$. Cl: confidence interval.

one $(0.5 \%)$ had central nervous system (CNS) recurrence, seven $(3.4 \%)$ had visceral recurrence and non-visceral without CNS involvement, and one $(0.5 \%)$ presented visceral and nonvisceral recurrence with CNS involvement.

\section{RFS and OS}

In an 11-year follow-up, RFS in invasive lobular cancer was $89.4 \%$ with a mean of $126 \pm 2.25$ months $(95 \%$ confidence interval (CI): 121.59 - 130.43 months). OS in invasive lobular carcinoma was $96.1 \%$.

\section{Survival by lymph node involvement}

According to the lymph node characteristics, the best prognosis in RFS was in patients with negative nodes 95.2\%, 132.06 \pm 1.93 months (95\% CI: 128.27 - 135.86 months) vs. 50\%, $85.89 \pm 9.59$ months (95\% CI: 67.08 - 104.69 months) with four or more positive nodes $(\mathrm{P}=0.0001)$, and OS was 98.6$100 \%$ vs. $75 \%$, respectively $(\mathrm{P}=0.0001)$ (Fig. 1$)$.

\section{Survival by tumor size}

Regarding tumor size, an RFS of $98.3 \%, 135.89 \pm 0.98$ months (95\% CI: 133.97 - 137.82 months) was observed in those measuring $\leq 2 \mathrm{~cm}$ vs. $60 \%, 74.01 \pm 9.54$ months $(95 \% \mathrm{CI}$ : $55.31-92.72$ months $)$ in a tumor size $>5 \mathrm{~cm}(\mathrm{P}=0.0001)$, and OS of $99.2 \%, 139.5 \pm 1$ months (95\% CI: 137 - 142 months) in tumor size $\leq 2 \mathrm{~cm}$ vs. $66.7 \%, 80.7 \pm 2$ months (95\% CI: 133 -
139 months $)$ in those $>5 \mathrm{~cm}(\mathrm{P}=0.0001)$ (Fig. 2).

\section{Survival by clinical stage}

RFS in patients with localized disease CS I - IIB (T2N1) was $>90 \%$ compared to clinical stage IIIC and IV where the RFS was $25-50 \%(\mathrm{P}=0.0001)$. OS was high in clinical stage IA IIA (93-100\%) and lower in CS IV (25\%) being statistically significant $(\mathrm{P}=0.0001)$.

\section{Survival by immunohistochemical characteristics}

The negative vs. positive estrogen receptor (ER) presented an RFS of $87.5 \%$ vs. $89.5 \%$, respectively $(\mathrm{P}=0.29)$, and OS was $93.8 \%$ vs. $96.3 \%$, respectively $(\mathrm{P}=0.52)$. It was also reported that the RFS in negative progesterone receptors (PRs) was $86.2 \%$ vs. $89.9 \%$ in positive PRs ( $\mathrm{P}=0.11$ ), and OS was $86.2 \%$ vs. $97.8 \%$, respectively $(\mathrm{P}=0.002)$. Negative Her2 was related to an RFS of $92.1 \%, 128.75 \pm 2.16$ months $(95 \%$ CI: 124.50 - 132.99 months) vs. $72.4 \%, 108.01 \pm 8.35$ months $(95 \% \mathrm{CI}$ : $91.63-124.39$ months) in positive Her2 $(\mathrm{P}=0.0001)$, and had better OS (98.3\%, $138 \pm 1$ months (95\% CI: 136 - 141 months)) with negative Her2 vs. positive Her2 $(82.8 \%, 118 \pm 2$ months (95\% CI: 133 - 139 months), $\mathrm{P}=0.0001)$ ) (Fig. 3). Ki67 proliferation index $>15 \%$ was associated with an RFS of $84.3 \%$, $118.17 \pm 4.14$ months (95\% CI: $100.04-126.29$ months) vs. 93.2\%, $130.69 \pm 2.23$ months (95\% CI: 126.32 - 135.07 months) with a Ki67 $\leq 14 \%(\mathrm{P}=0.005)$, and OS was 94.4\%, $129 \pm 3$ months (95\% CI: 124 - 135 months) vs. 97.5\%, $138 \pm 2$ months (95\% CI: 134 - 141 months), respectively $(\mathrm{P}=0.21)$. 


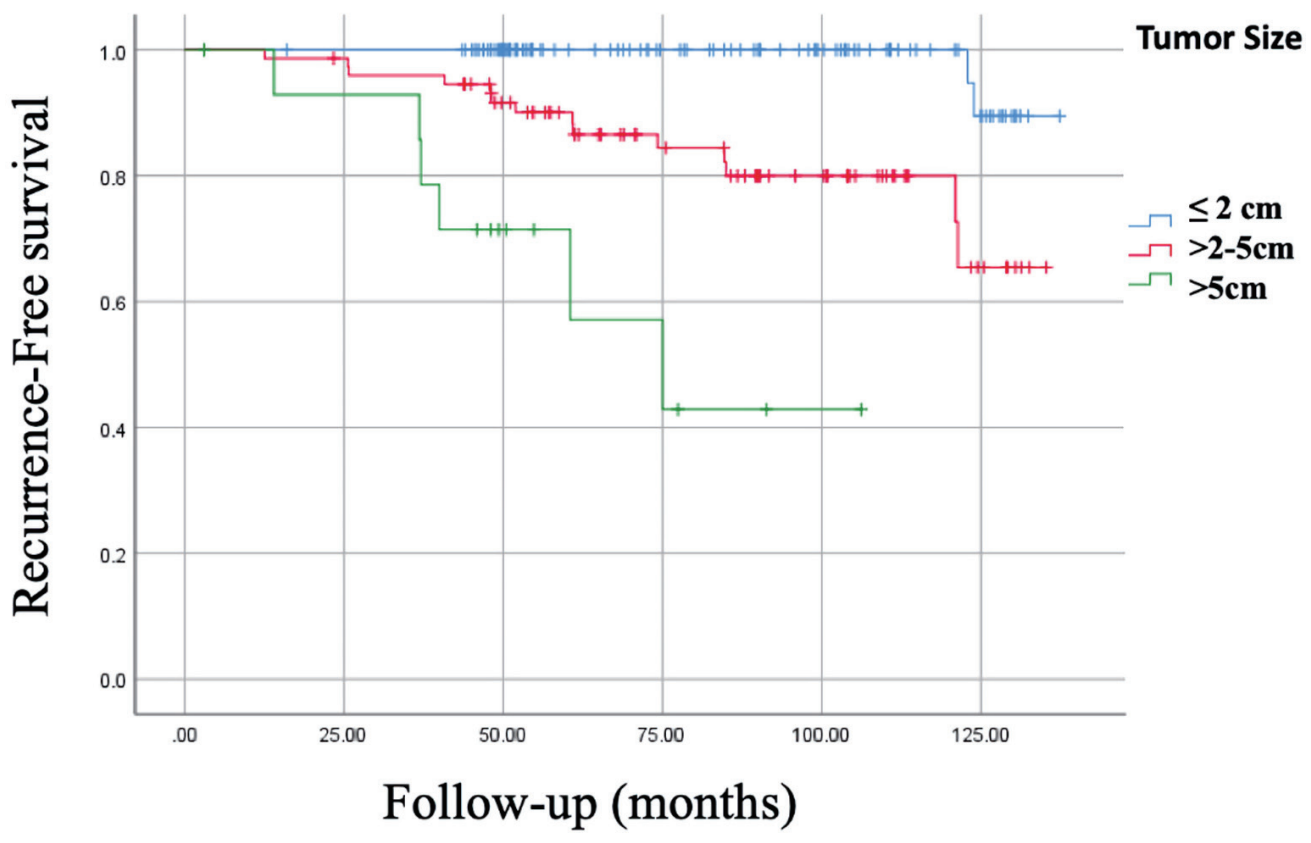

Figure 2. Kaplan-Meier curve of recurrence-free survival (RFS) of tumor size. RFS of tumor $\leq 2 \mathrm{~cm}: 98.3 \%, 135.89 \pm 0.98$ months (95\% Cl: $133.97-137.82$ months). RFS of tumor > 2 - $5 \mathrm{~cm}: 81.1 \%, 117.28 \pm 4.28$ months (95\% Cl: $108.89-125.68$ months). RFS of tumor $>5 \mathrm{~cm}: 60 \%, 74.01 \pm 9.54$ months $(95 \% \mathrm{Cl}: 55.31-92.72$ months), $\mathrm{P}=0.0001$. Cl: confidence interval.

\section{Survival by molecular subtypes}

Regarding the molecular subtypes, the RFS was higher in the luminal A (95.4\%), the worst being the worst in the pure Her2 $(\mathrm{P}=0.0001)$, and all molecular subtype had an OS $>90 \%$, including triple negative and Her2 $(\mathrm{P}=0.11)$.

\section{Survival by histological grade}

In addition, the histological grade correlated with the RFS being $100 \%$ for those well differentiated vs. $73.6 \%$ for the poorly differentiated ( $\mathrm{P}=0.0001)$, and OS was $100 \%$ vs. $90.6 \%$, respectively $(\mathrm{P}=0.049)$ (Fig. 4).

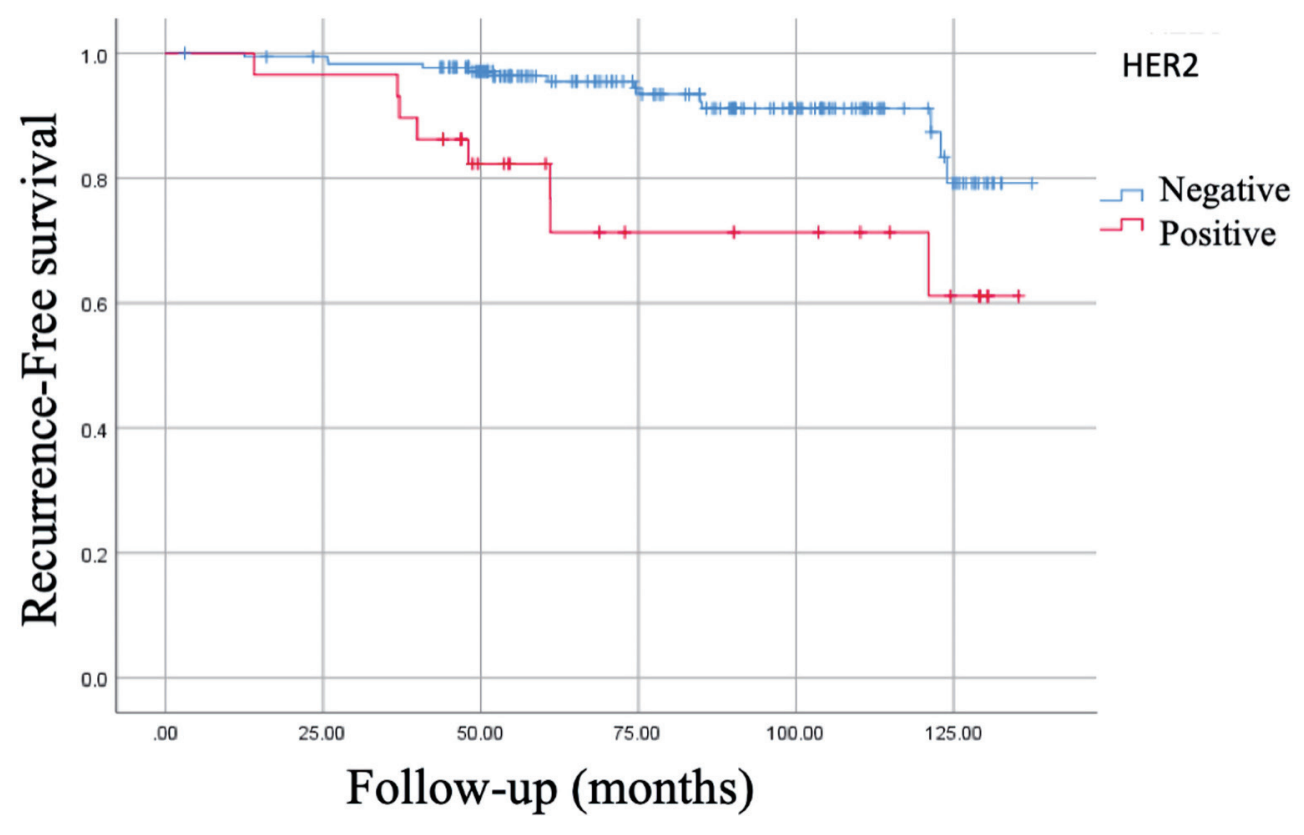

Figure 3. Kaplan-Meier curve of recurrence-free survival (RFS) of Her2. RFS of Her2 (-): $92.1 \%, 128.75 \pm 2.16$ months (95\% Cl: $124.50-132.99$ months). RFS of Her2 (+): $72.4 \%, 108.01 \pm 8.35$ months (95\% Cl: $91.63-124.39$ months), P $=0.0001 . \mathrm{Cl}$ : confidence interval. 


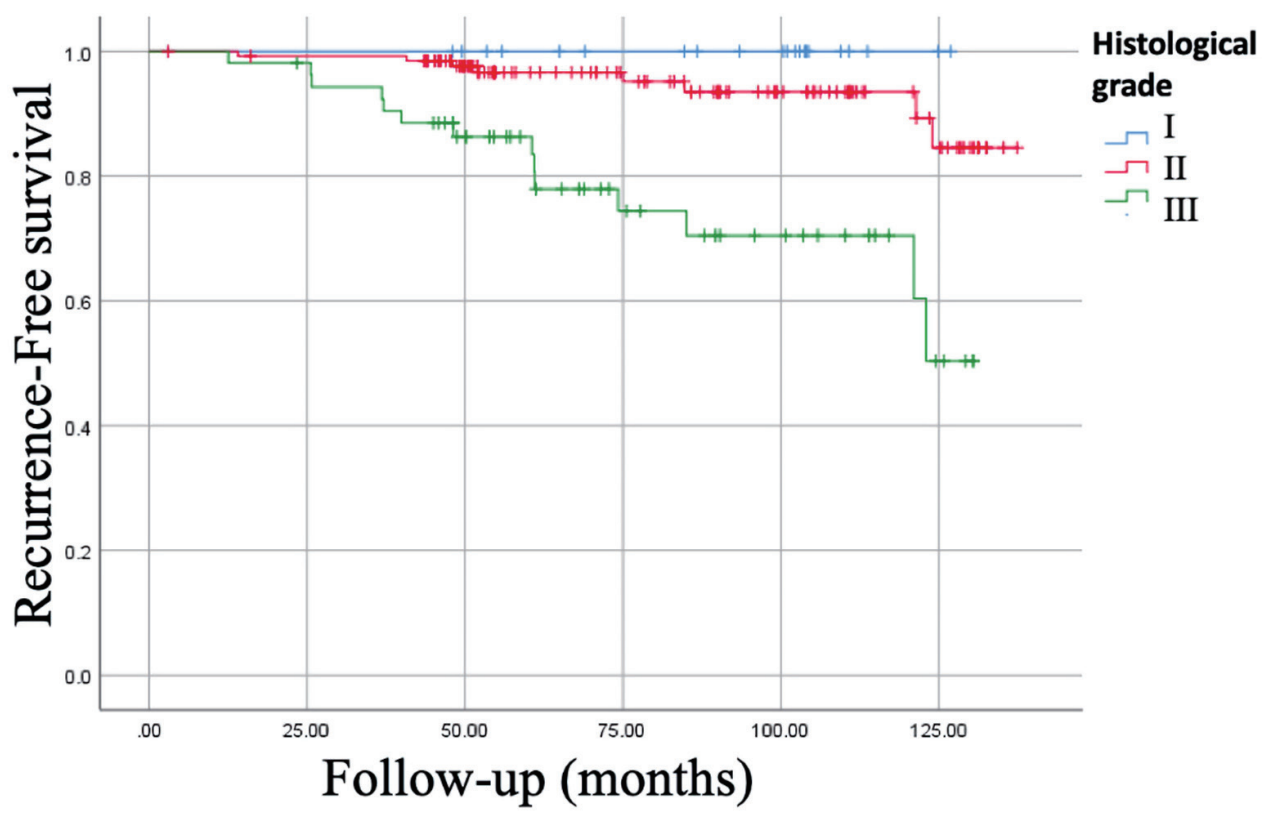

Figure 4. Kaplan-Meier curve of recurrence-free survival (RFS) of histological grade. RFS for well differentiated (histological grade I) was of $100 \%$ vs. $73.6 \%$ for the poorly differentiated (histological grade III), $P=0.0001$.

\section{Survival by postoperative histopathological characteristics}

Postoperative positive margin vs. negative margin, no significant difference was observed in RFS $(87.1 \%$ vs. $89.8 \%$, respectively), with a $\mathrm{P}=0.99$, and OS was $96.8 \%$ vs. $96 \%$, respectively $(\mathrm{P}=0.80)$. Negative lymph vascular invasion (LVI) increases the RFS of $91.8 \%$ vs. $81.6 \%$ in those who had positive LVI $(\mathrm{P}=0.032)$; however, there was no significant difference in OS $(96.2 \%$ vs. $95.9 \%, \mathrm{P}=0.032)$. Negative perineural invasion (PNI) demonstrated RFS of $90.2 \%$ vs. $84.8 \%$ with positive PNI $(\mathrm{P}=0.2)$, and OS of $96.6 \%$ vs. $93.9 \%$, respectively $(\mathrm{P}=0.53)$.

\section{Survival by E-cadherin expression}

The rate of positive expression of E-cadherin was associated with an increase in the RFS of $97.4 \%$, with a mean of 128.6 \pm 2.4 months (95\% CI: 123.75 - 133.45 months) compared to the absence of expression E-cadherin: signal log ratio (SLR) $68.9 \%$, a mean of $95 \pm 6$ months (95\% CI: 83.28 - 106.88 months), $\mathrm{P}<0.001$. When the OS was analyzed, the presence of E-cadherin expression increased the OS of $100 \%$ vs. $86.9 \%$ with the absence, $\mathrm{P}=0.015$ (Figs. 5, 6).

\section{Discussion}

Infiltrating lobular carcinomas have a higher frequency of bilaterality and multicentricity than infiltrating ductal carcinomas; arise in older women and are larger and better differentiated tumors. As a rule, invasive lobular carcinomas are ER-positive, with variant lesions showing occasional variable expression. As a group, invasive lobular carcinomas tend to metastasize later than invasive duct carcinomas $[12,13]$.

Several population studies and randomized trials show an increased incidence of invasive lobular breast cancer in women over 60 years of age, menopausal and with the most frequent molecular subtype luminal A, as reported in this study in the Mexican population [14-17]. Macari et al reported that breast carcinoma occurs at an earlier age in Mexican women compared to women in the USA. Hormone-positive tumors were found to be more prevalent in older patients, while high-grade tumors were more frequently identified in younger patients [18].

In Jamaica, patients in the age group less than 50 years were more likely to have advanced stage, high histological grade cancers compared to the older age blocks (95\% CI: $0.039-0.902, \mathrm{P}=0.033)$, associated with poor prognostic [19].

Breast cancer in African women differs from that of white and Mexican women. More than half $(62.5 \%)$ are premenopausal Nigerian women at presentation, compared to Mexican women in whom $72.9 \%$ are postmenopausal in this study. Most of the patients (Nigerian women) presented in the last stage of the disease, stage III (66.9\%) and stage IV (18.3\%), and in Mexican women stages III and IV were reported (12\%) in our study, which conditions a worse prognosis in Nigerian women [20].

Invasive lobular breast cancer is frequently diagnosed in early stages, especially in institutions where breast cancer screening is performed routinely, which allows patients with these pathologies to have a better RFS and OS $>90 \%$ as reported in this study, and presents metastasis years later, which conditions worse prognosis $[1,5,12,16,21]$.

In our study, $98(47.3 \%)$ of the patients underwent modified radical mastectomy and $106(51.2 \%)$ with breast-conserving surgery. This is due to the high frequency of early clinical presentation of the disease and the decision-making as a whole with the patient for breast conservation; type of surgery is per- 


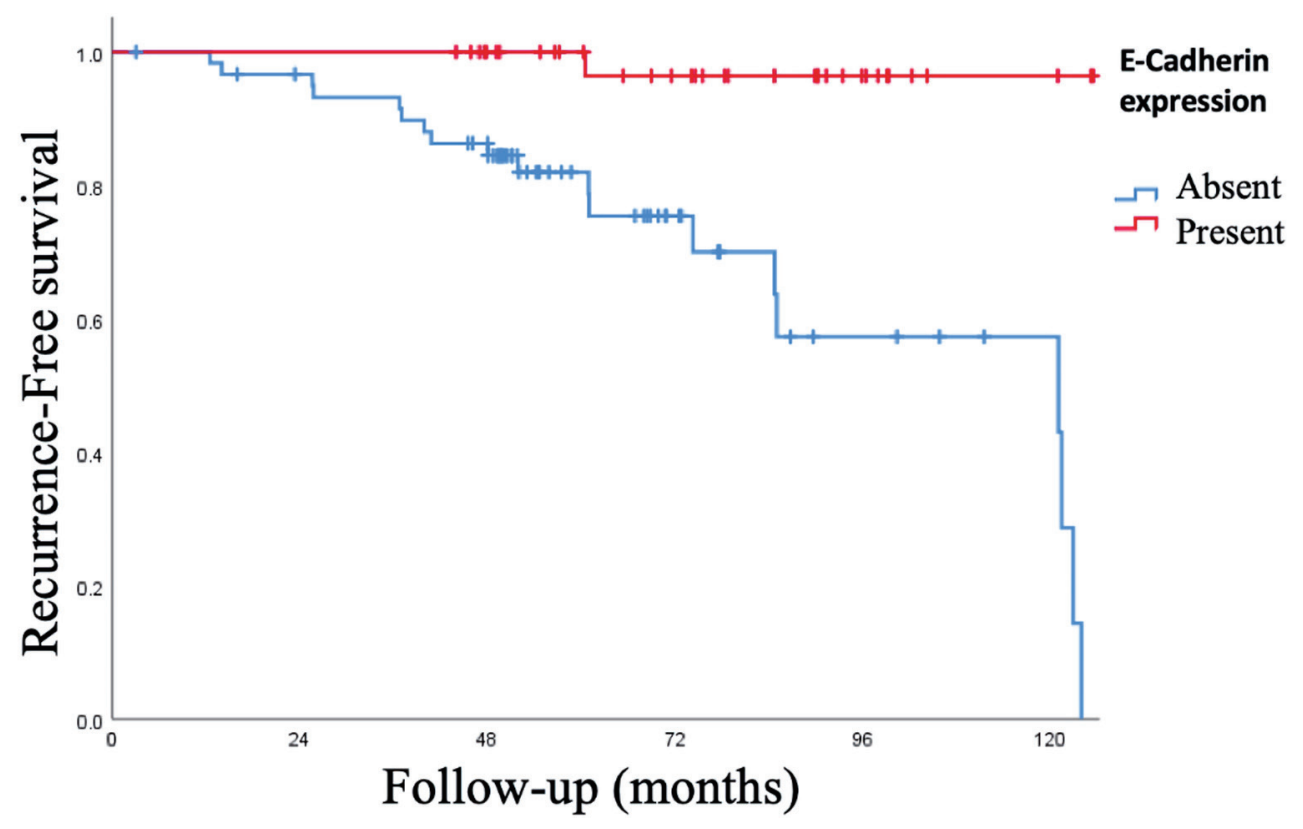

Figure 5. Kaplan-Meier curve of recurrence-free survival (RFS) of expression of epithelial-cadherin (E-cadherin). The positive expression of E-cadherin was associated with an increase in the RFS of $97.4 \%$, with a mean of $128.6 \pm 2.4$ months (95\% Cl: $123.75-133.45$ months) compared to the absence of expression E-cadherin: signal log ratio (SLR) $68.9 \%$, a mean of $95 \pm 6$ months (95\% Cl: 83.28 - 106.88 months), $\mathrm{P}<0.001$. Cl: confidence interval.

formed less frequently in other institutions [6-12].

\section{Prognostic role of lymph node involvement}

The prognostic role of micro metastatic lymph node involvement was demonstrated in a large meta-analysis of 58 studies.
Patients with microscopic pathological lymph node involvement had a higher risk of death compared to patients with pN0 disease (hazard ratio (HR): 1.44 ; $95 \%$ CI: 1.29 - 1.62); in addition the number of nodes has been correlated with the prognosis in recurrence and survival, so it is currently one of the clinicopathological characteristics with the greatest prognostic impact [22-24].

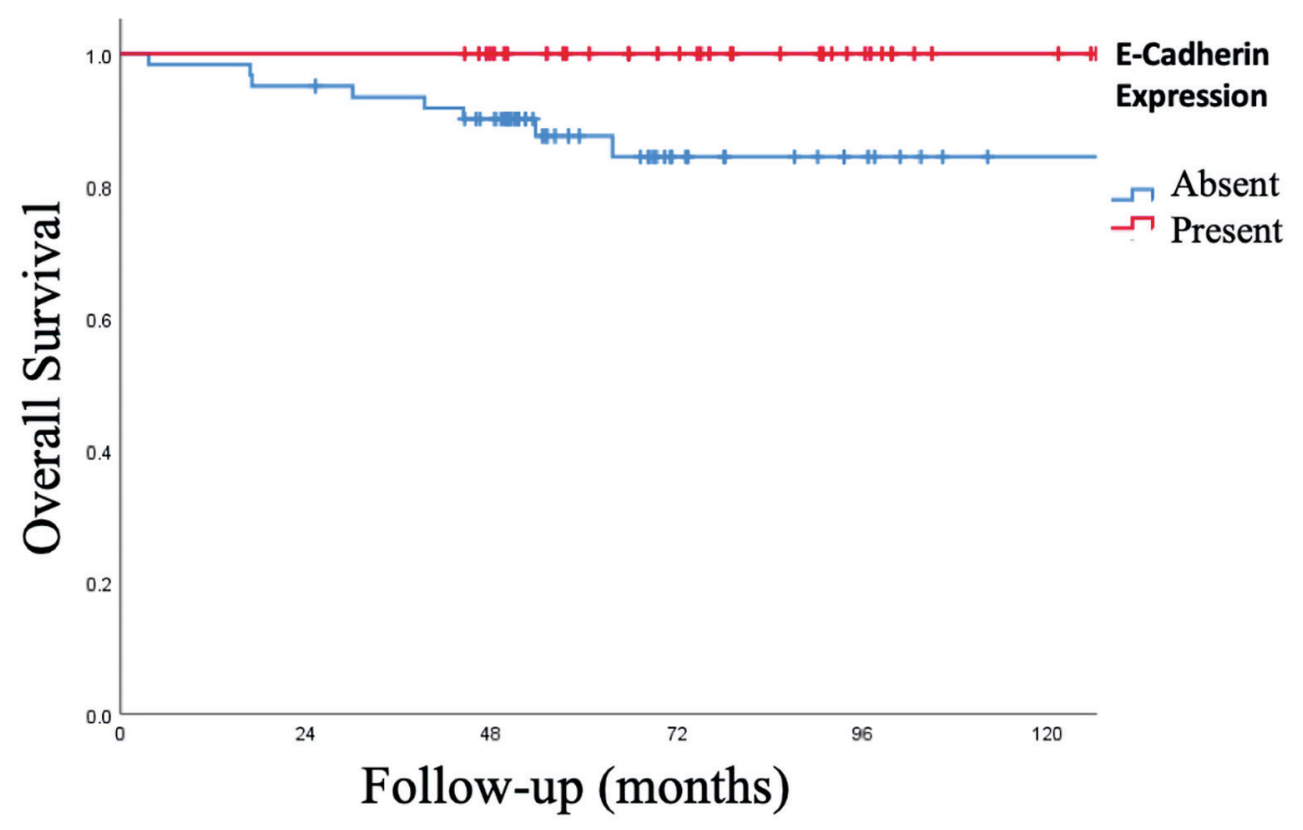

Figure 6. Kaplan-Meier curve of overall survival (OS) of expression of epithelial-cadherin (E-cadherin). The presence of Ecadherin expression increased the OS of $100 \%$ vs. $86.9 \%$ with the absence, $P=0.015$. 


\section{Prognostic role of histological grade}

In relation to the histological grade, worse RFS $(73.6 \%, \mathrm{P}$ $=0.0001)$ and $\operatorname{OS}(90.6 \%, \mathrm{P}=0.049)$ were observed in the poorly differentiated (grade 3 ) ones. As reported in a study that included more than 2,200 cases of operable breast cancer, where there was a correlation between histological grade and worsening results, with an HR for worsening breast cancerspecific survival (CSS) of 1.6 for grade 2 cancers vs. $1(95 \%$ CI: $1.1-2.5)$ and 3.9 for grade 3 vs. grade 1 cancers $(95 \% \mathrm{CI}$ : 2.6 - 5.8). The correlation persisted after multivariate adjustment for other prognostic indications, including lymph node involvement, tumor size, and vascular invasion [25, 26].

\section{Prognostic role of molecular subtypes and postoperative histopathological characteristics}

Because the largest population was luminal A and B, which is correlated with a good prognosis; when analyzing the postsurgical characteristics, it was observed that the perineural invasion and positive margin did not show worse RFS or OS compared to those that did not have these characteristics. Better RFS $(91.8 \%$ vs. $81.6 \%, \mathrm{P}=0.032)$ was only observed in those who did not have LVI; however, there was no greater significant difference in $\mathrm{OS}(\mathrm{P}=0.84)$. These data seem to correlate with a population study of more than 15,000 patients, where LVI was significantly associated with other adverse prognostic factors (tumor size, grade, positive lymph node status, ductal histology, ER negativity). In the absence of these other factors, LVI had no effect on survival. At 5 years, $98 \%$ of the patients without LVI were alive vs. $94.1 \%$ of the patients with LVI [2729].

There is a meta-analysis where it was observed that $\mathrm{Ki} 67$ $>14 \%$ is associated with a higher risk of relapse in node-positive disease (HR: 1.59, 95\% CI: 1.35 - 1.87) and with disease with negative nodes (HR: 2.31, 95\% CI 1.83 - 2.92); as well as worse survival in node-positive disease (HR of death: 2.33, 95\% CI: $1.83-2.95$ ) and with node-negative disease (HR: $2.54,95 \%$ CI: $1,65-3.91)$; data are reproduced in this study with relation $[30,31]$.

\section{Prognostic role of immunohistochemical characteristics}

In our study, PR expression did not show benefit in RFS ( $\mathrm{P}=$ 0.11 ), although it did report an improvement in OS in PR $(+)$ of $97.8 \%$ vs. $86.2 \%$ in PR (-), P $=0.002$. This was demonstrated in a large population cohort study that included more than 1,000 women with early breast cancer, who underwent primary surgery with curative intent. The absence of RP expression was associated with a poorer prognosis for OS, CSS, and disease-free survival (DFS) [32].

Where an important benefit was observed in the RFS and OS, it was in those patients who had negative Her2 (RFS: $92.1 \%$ vs. $72.4 \%, \mathrm{P}=0.0001$ and $\mathrm{OS}: 98.3 \%$ vs. $82.8 \%, \mathrm{P}=$ $0.0001)$. In the literature, it is reported that in the absence of systemic therapy, Her2 overexpression is a poor prognostic marker in patients with pathologically node-positive and nodenegative breast cancer. Furthermore, the data suggest that Her2 retains prognostic value even in the presence of small tumors $\leq 1 \mathrm{~cm}[33,34]$.

\section{Prognostic role of E-cadherin expression}

Changes in cell adhesion are the main mechanism of invasion and metastasis of a malignant tumor. Decreased cell adhesion is an important factor that leads to tumor infiltration and metastasis [6-9].

E-cadherin is a type of cell adhesion glycoprotein. It is not only an inhibitor of tumor cell invasion and metastasis, it is also an inhibitor of normal cell growth. Studies have found that when the epithelium-mesenchymal transition occurs in cancer cells, the expression of E-cadherin decreases or shows a functional loss, causing decreased cell adhesion, loss of polarity, and infiltration of surrounding tissue growth, and can be transferred to bone, liver, lung and brain tissue [35-37]. Moussa et al reported prognostic role of epithelial-mesenchymal transition markers in transitional cell carcinoma and squamous cell carcinoma variants of bladder carcinoma. They concluded that poor prognosis was evident in association with reduced E-cadherin, positive nuclear $\beta$-catenin/reduced membranous $\beta$-catenin, zinc-finger E-box-binding homeobox 1 (ZEB1), ZEB2-positive cases as well patients with elevated p63 expression $(\mathrm{P}<0.001)[38]$.

E-cadherin has become one of the most important research points among members of the cadherin family. Studies have found that E-cadherin is involved in the early appearance, infiltration, and metastasis of different tumors. The expression of E-cadherin is closely associated with the invasion and metastasis of various tumors and their clinical prognoses [39, 40].

The interpretation of the stain for E-cadherin is debatable. In the immunohistochemical method, the biggest problem remains the subjective evaluation of pathomorphologists and their experience. There are no criteria accepted as synonyms to consider the evaluation of the level of absence of E-cadherin. Most of the authors, as in the study presented, assume that the correct functioning of the cells requires the presence of E-cadherin in at least $70 \%$ of the stained cells. Its expression in less than $70 \%$ of the cells evaluated is treated as the absence of E-cadherin [41].

As has been shown in many investigations, the expression of E-cadherin is very rare in tumors with a high potential for malignancy. Breast cancer has been studied; however most of the literature has focused on invasive ductal breast cancer where it is more frequent, not so in infiltrating lobular carcinoma, where the frequency of expression of E-cadherin is very low, such as reported in our study [39-41].

The expression of E-cadherin was analyzed in $48.3 \%$ (100/207 patients), and positive expression was reported in 39 patients $(18.8 \%)$ and negative expression in $29.4 \%$ of the patients who underwent immunohistochemistry for E-cadherin. The results of the present study suggested that the absence of E-cadherin expression was positively associated with lymph node metastases. The rate of positive expression of E-cadherin was associated with an increase in RFS of $97.4 \%$, with a mean 
of $128.6 \pm 2.4$ month (95\% CI: 123.75 - 133.45 months) compared to the absence of E-cadherin expression: RFS of $68.9 \%$, a mean of $95 \pm 6$ months (95\% CI: 83.28 - 106.88 months), $\mathrm{P}$ $<0.001$. In the study by De Leeuw et al, they reported a significant correlation with the absence of E-cadherin and lymph node metastases, as well as an impact on survival [42].

When the OS was analyzed, the presence of E-cadherin expression increased the OS of $100 \%$ vs. $86.9 \%$ with the absence, $\mathrm{P}=0.015$. The absence of E-cadherin expression was more frequent in patients with distant metastatic disease. When evaluating E-cadherin in breast cancer, Brzozowska et al observed a decrease in OS and DFS in patients who had no E-cadherin expression when compared with those who did have E-cadherin expression [43].

Many studies have evaluated the association between the absence of E-cadherin expression and the prognosis of patients with breast cancer. However, the results are inconsistent. Li et al reported in their 2017 meta-analysis [44] the results of a total of 33 individual studies that included 7,353 breast cancer patients. It was concluded that the absence of E-cadherin expression significantly predicted poor OS (HR: 1.79, 95\% CI: 1.41 - 2.27) and poor DFS (HR: 1.62, 95\% CI: 1.31 - 1.99). Furthermore, the absence of E-cadherin expression was correlated with tumor size (OR: 1.38), lymph node status (OR: 1.55), TNM stage (OR: 2.44), and histological grade (OR: 1.44).

Due to the heterogeneity of the studies, since they include lobular and ductal breast cancer, as well as the range to consider absence of E-cadherin expression by immunohistochemistry $(5-70 \%)$ and the small population that has been studied, about all in lobular cancer, a prospective study is required, with a larger population in which the absence or presence of E-cadherin expression is determined with a standard cut-off point by immunohistochemistry to establish homogeneity in the results.

Understanding these mechanisms and further investigating the findings of this study will help confirm these results and determine other associated important findings. More research is required to properly understand decreased cell adhesion.

\section{Conclusions}

Results of the analysis in the presented study indicate that positive expression of E-cadherin correlates with an improvement in OS and RFS. Therefore, it should be considered as a new prognostic tool in invasive lobular breast cancer in Mexican women. The prognostic impact of the different clinicopathological characteristics known worldwide was confirmed.

\section{Acknowledgments}

Thanks to the Medical Sur Hospital, for their support in data collection.

\section{Financial Disclosure}

None to declare.

\section{Conflict of Interest}

The authors have no conflict of interest to declare.

\section{Informed Consent}

Informed consents were obtained.

\section{Author Contributions}

The author Ricardo Fernandez-Ferreira collected the data, analysis and critical revision of the content, as well as the final approval of the version to be published. Daniel Motola-Kuba, Jose-Manuel Ruiz-Morales, Gabriela Alvarado-Luna, Ileana Mac Kinney-Novelo and Kevin-Joseph Fuentes-Calvo participated in the information search and contributed in the discussion, as well as the final approval of the version to be published. WendyRossemary Munoz-Montano performed the statistical analysis and reported the findings from the database. Rita Dorantes-Heredia carried out an exhaustive review of the histopathological characteristics of cancer and analysis of the article. All authors agree to be responsible for all aspects of the job to ensure that questions related to the accuracy or completeness of any part of the job are properly investigated and resolved.

\section{Data Availability}

The authors declare that data supporting the findings of this study are available within the article.

\section{Abbreviations}

BC: breast cancer; RFS: recurrence-free survival; OS: overall survival; E-cadherin: epithelial cadherin; CS: clinical stage; CNS: central nervous system; LVI: lymph vascular invasion; PNI: perineural invasion; CSS: cancer-specific survival; DFS: disease-free survival

\section{References}

1. Sung H, Ferlay J, Siegel RL, Laversanne M, Soerjomataram I, Jemal A, Bray F. Global cancer statistics 2020: GLOBOCAN estimates of incidence and mortality worldwide for 36 cancers in 185 countries. CA Cancer J Clin. 2021;71(3):209-249.

2. Siegel RL, Miller KD, Jemal A. Cancer statistics, 2019. CA Cancer J Clin. 2019;69(1):7-34.

3. Kohler BA, Ward E, McCarthy BJ, Schymura MJ, Ries LA, Eheman C, Jemal A, et al. Annual report to the nation on the status of cancer, 1975-2007, featuring tumors of the brain and other nervous system. J Natl Cancer Inst. 2011;103(9):714-736.

4. Kohler BA, Sherman RL, Howlader N, Jemal A, Ryerson 
AB, Henry KA, Boscoe FP, et al. Annual report to the nation on the status of cancer, 1975-2011, featuring incidence of breast cancer subtypes by race/ethnicity, poverty, and state. J Natl Cancer Inst. 2015;107(6):djv048.

5. Orvieto E, Maiorano E, Bottiglieri L, Maisonneuve P, Rotmensz N, Galimberti V, Luini A, et al. Clinicopathologic characteristics of invasive lobular carcinoma of the breast: results of an analysis of 530 cases from a single institution. Cancer. 2008;113(7):1511-1520.

6. Yoshida R, Kimura N, Harada Y, Ohuchi N. The loss of E-cadherin, alpha- and beta-catenin expression is associated with metastasis and poor prognosis in invasive breast cancer. Int J Oncol. 2001;18(3):513-520.

7. Li DM, Feng YM. Signaling mechanism of cell adhesion molecules in breast cancer metastasis: potential therapeutic targets. Breast Cancer Res Treat. 2011;128(1):7-21.

8. Ye Y, Tian H, Lange AR, Yearsley K, Robertson FM, Barsky SH. The genesis and unique properties of the lymphovascular tumor embolus are because of calpain-regulated proteolysis of E-cadherin. Oncogene. 2013;32(13):17021713.

9. Tian MY, Wang LH, Zhang X. Expressions of E-cadherin and vimentin in lung cancer tissue and their relationship to epithelial-mesenchymal transition. Chin J Biol. 2011;24:1068-1071 (In Chinese).

10. Li CI, Uribe DJ, Daling JR. Clinical characteristics of different histologic types of breast cancer. Br J Cancer. 2005;93(9):1046-1052.

11. Winchester DJ, Chang HR, Graves TA, Menck HR, Bland KI, Winchester DP. A comparative analysis of lobular and ductal carcinoma of the breast: presentation, treatment, and outcomes. J Am Coll Surg. 1998;186(4):416-422.

12. Pestalozzi BC, Zahrieh D, Mallon E, Gusterson BA, Price KN, Gelber RD, Holmberg SB, et al. Distinct clinical and prognostic features of infiltrating lobular carcinoma of the breast: combined results of 15 International Breast Cancer Study Group clinical trials. J Clin Oncol. 2008;26(18):3006-3014.

13. Moran MS, Yang Q, Haffty BG. The Yale University experience of early-stage invasive lobular carcinoma (ILC) and invasive ductal carcinoma (IDC) treated with breast conservation treatment (BCT): analysis of clinical-pathologic features, long-term outcomes, and molecular expression of COX-2, Bcl-2, and p53 as a function of histology. Breast J. 2009;15(6):571-578.

14. Li CI, Moe RE, Daling JR. Risk of mortality by histologic type of breast cancer among women aged 50 to 79 years. Arch Intern Med. 2003;163(18):2149-2153.

15. Partridge AH, Hughes ME, Warner ET, Ottesen RA, Wong YN, Edge SB, Theriault RL, et al. Subtype-dependent relationship between young age at diagnosis and breast cancer survival. J Clin Oncol. 2016;34(27):33083314.

16. Bastiaannet E, Liefers GJ, de Craen AJ, Kuppen PJ, van de Water W, Portielje JE, van der Geest LG, et al. Breast cancer in elderly compared to younger patients in the Netherlands: stage at diagnosis, treatment and survival in 127,805 unselected patients. Breast Cancer Res Treat. 2010;124(3):801-807.
17. van de Water W, Markopoulos C, van de Velde CJ, Seynaeve C, Hasenburg A, Rea D, Putter H, et al. Association between age at diagnosis and disease-specific mortality among postmenopausal women with hormone receptorpositive breast cancer. JAMA. 2012;307(6):590-597.

18. Macari A, Soberanis-Pina P, Varela-Santoyo E, ValleSanchez MA, Leal-Hidalgo JL, Torres-Guillen VM, Motola-Kuba D, et al. Prevalence and molecular profile of breast carcinoma using immunohistochemistry markers in Mexican women. World J Oncol. 2021;12(4):119-123.

19. Copeland J, Oyedeji A, Powell N, Cherian CJ, Tokumaru Y, Murthy V, Takabe K, et al. Breast Cancer in Jamaica: Stage, Grade and molecular subtype distributions across age blocks, the implications for screening and treatment. World J Oncol. 2021;12(4):93-103.

20. Adeniji AA, Dawodu OO, Habeebu MY, Oyekan AO, Bashir MA, Martin MG, Keshinro SO, et al. Distribution of breast cancer subtypes among Nigerian women and correlation to the risk factors and clinicopathological characteristics. World J Oncol. 2020;11(4):165-172.

21. Cristofanilli M, Gonzalez-Angulo A, Sneige N, Kau SW, Broglio K, Theriault RL, Valero V, et al. Invasive lobular carcinoma classic type: response to primary chemotherapy and survival outcomes. J Clin Oncol. 2005;23(1):4148.

22. Andersson Y, Frisell J, Sylvan M, de Boniface J, Bergkvist L. Breast cancer survival in relation to the metastatic tumor burden in axillary lymph nodes. J Clin Oncol. 2010;28(17):2868-2873.

23. de Boer M, van Dijck JA, Bult P, Borm GF, Tjan-Heijnen VC. Breast cancer prognosis and occult lymph node metastases, isolated tumor cells, and micrometastases. J Natl Cancer Inst. 2010;102(6):410-425.

24. Weaver DL, Ashikaga T, Krag DN, Skelly JM, Anderson SJ, Harlow SP, Julian TB, et al. Effect of occult metastases on survival in node-negative breast cancer. N Engl J Med. 2011;364(5):412-421.

25. Elston CW, Ellis IO. Pathological prognostic factors in breast cancer. I. The value of histological grade in breast cancer: experience from a large study with long-term follow-up. Histopathology. 1991;19(5):403-410.

26. Rakha EA, El-Sayed ME, Lee AH, Elston CW, Grainge MJ, Hodi Z, Blamey RW, et al. Prognostic significance of Nottingham histologic grade in invasive breast carcinoma. J Clin Oncol. 2008;26(19):3153-3158.

27. Pinder SE, Ellis IO, Galea M, O'Rouke S, Blamey RW, Elston CW. Pathological prognostic factors in breast cancer. III. Vascular invasion: relationship with recurrence and survival in a large study with long-term follow-up. Histopathology. 1994;24(1):41-47.

28. Ejlertsen B, Jensen MB, Rank F, Rasmussen BB, Christiansen P, Kroman N, Kvistgaard ME, et al. Populationbased study of peritumoral lymphovascular invasion and outcome among patients with operable breast cancer. J Natl Cancer Inst. 2009;101(10):729-735.

29. Viale G, Giobbie-Hurder A, Gusterson BA, Maiorano E, Mastropasqua MG, Sonzogni A, Mallon E, et al. Adverse prognostic value of peritumoral vascular invasion: is it abrogated by adequate endocrine adjuvant therapy? Re- 
sults from two International Breast Cancer Study Group randomized trials of chemoendocrine adjuvant therapy for early breast cancer. Ann Oncol. 2010;21(2):245-254.

30. Luporsi E, Andre F, Spyratos F, Martin PM, Jacquemier J, Penault-Llorca F, Tubiana-Mathieu N, et al. Ki-67: level of evidence and methodological considerations for its role in the clinical management of breast cancer: analytical and critical review. Breast Cancer Res Treat. 2012;132(3):895-915.

31. de Azambuja E, Cardoso F, de Castro G, Jr., Colozza M, Mano MS, Durbecq V, Sotiriou C, et al. Ki-67 as prognostic marker in early breast cancer: a meta-analysis of published studies involving 12,155 patients. Br J Cancer. 2007;96(10):1504-1513.

32. Purdie CA, Quinlan P, Jordan LB, Ashfield A, Ogston S, Dewar JA, Thompson AM. Progesterone receptor expression is an independent prognostic variable in early breast cancer: a population-based study. Br J Cancer. 2014;110(3):565-572.

33. Chia S, Norris B, Speers C, Cheang M, Gilks B, Gown AM, Huntsman D, et al. Human epidermal growth factor receptor 2 overexpression as a prognostic factor in a large tissue microarray series of node-negative breast cancers. J Clin Oncol. 2008;26(35):5697-5704.

34. Schettini F, Pascual T, Conte B, Chic N, Braso-Maristany F, Galvan P, Martinez O, et al. HER2-enriched subtype and pathological complete response in HER2-positive breast cancer: A systematic review and meta-analysis. Cancer Treat Rev. 2020;84:101965.

35. Wendt MK, Taylor MA, Schiemann BJ, Schiemann WP. Down-regulation of epithelial cadherin is required to initiate metastatic outgrowth of breast cancer. Mol Biol Cell. 2011;22(14):2423-2435.

36. Rubin MA, Mucci NR, Figurski J, Fecko A, Pienta KJ,
Day ML. E-cadherin expression in prostate cancer: a broad survey using high-density tissue microarray technology. Hum Pathol. 2001;32(7):690-697.

37. Suciu C, Cimpean AM, Muresan AM, Izvernariu D, Raica M. E-cadherin expression in invasive breast cancer. Rom J Morphol Embryol. 2008;49(4):517-523.

38. Moussa RA, Khalil EZI, Ali AI. Prognostic role of epithelial-mesenchymal transition markers "E-Cadherin, betaCatenin, ZEB1, ZEB2 and p63" in Bladder Carcinoma. World J Oncol. 2019;10(6):199-217.

39. Siitonen SM, Kononen JT, Helin HJ, Rantala IS, Holli $\mathrm{KA}$, Isola JJ. Reduced E-cadherin expression is associated with invasiveness and unfavorable prognosis in breast cancer. Am J Clin Pathol. 1996;105(4):394-402.

40. Gamallo C, Palacios J, Suarez A, Pizarro A, Navarro P, Quintanilla M, Cano A. Correlation of E-cadherin expression with differentiation grade and histological type in breast carcinoma. Am J Pathol. 1993;142(4):987-993.

41. Moll R, Mitze M, Frixen UH, Birchmeier W. Differential loss of E-cadherin expression in infiltrating ductal and lobular breast carcinomas. Am J Pathol. 1993;143(6):17311742.

42. De Leeuw WJ, Berx G, Vos CB, Peterse JL, Van de Vijver MJ, Litvinov S, Van Roy F, et al. Simultaneous loss of E-cadherin and catenins in invasive lobular breast cancer and lobular carcinoma in situ. J Pathol. 1997;183(4):404411.

43. Brzozowska A, Sodolski T, Duma D, Mazurkiewicz T, Mazurkiewicz M. Evaluation of prognostic parameters of E-cadherin status in breast cancer treatment. Ann Agric Environ Med. 2012;19(3):541-546.

44. Li Z, Yin S, Zhang L, Liu W, Chen B. Prognostic value of reduced E-cadherin expression in breast cancer: a metaanalysis. Oncotarget. 2017;8(10):16445-16455. 